\title{
Risk factors of neonatal mortality in Iran: a systematic review
}

\author{
Amin Daemi ${ }^{1}$, Hamid Ravaghi*1, Mehdi Jafari ${ }^{1,2}$ \\ Received: 16 Jan 2018 \\ Published: 24 Aug 2019
}

\begin{abstract}
Background: Reducing neonatal mortality is an important measure to reduce the overall under-five-years' mortality. Identifying the risk factors is the first step in this regard. This study performed with the aim of determining the risk factors of the neonatal mortality in Iran.

Methods: Databases of SID, MagIran, IranMedex, IronDoc and Google Scholar for the Persian resources and Scopus, Science Direct, PubMed, Ovid, EMBASE, ISI web of science and Cochrane for English resources were searched up to January 2017. The inclusion criteria were the studies analyzing at least one risk factor for neonatal mortality in Iran with a control group and multivariate regression analysis. Eight papers met the inclusion criteria. The risk factors were extracted and tabulated.

Results: Of the 1713 records retrieved, 8 were eligible to include in the analysis. Preterm birth, low birth weight, smoking and addiction, and anomaly were the important risk factors of neonatal mortality in Iran. Moreover, an extended list of potential risk factors identified on most of which the evidence was controversial and insufficient. The factors categorized into modifiable and identifiable ones.

Conclusion: On the modifiable risk factors, proper intervention, and on the non-modifiable ones, early detection and special care may be helpful in preventing the babies from death. Population-based studies with large sample size and multivariate analysis are needed to make clear the effect size of the identified risk factors.
\end{abstract}

Keywords: New born, Mortality, Risk factor, Iran

Conflicts of Interest: None declared

Funding: Iran University of Medical Sciences

\section{*This work has been published under CC BY-NC-SA 1.0 license. \\ Copyright $₫$ Iran University of Medical Sciences}

Cite this article as: Daemi A, Ravaghi H, Jafari M. Risk factors of neonatal mortality in Iran: a systematic review. Med J Islam Repub Iran. 2019 (24 Aug);33:87. https://doi.org/10.47176/mjiri.33.87

\section{Introduction}

One of the goals of the Millennium Development Goals (MDGs) was to reduce the under-five mortality by twothird by the year 2015 (1). Afterward, in the Sustainable Development Goals (SDGs) the target is repeated under the third goal "Ensure healthy lives and promote wellbeing for all at all ages" (2). Since about two third of the infant mortality (3) and about half of the under-five mortality (4) occur in the neonatal period (within 4 weeks after birth), to attain this target, countries must focus on reducing the neonatal mortality rate (NMR) (5). Moreover, a study i n 18 hospitals of Jordan reported that $37 \%$ of the neonatal mortalities are preventable and another 59\% are potentially preventable (6).

\footnotetext{
Corresponding author: Dr Hamid Ravaghi, ravaghi.h@iums.ac.ir

1. Department of Health Services Management, Iran University of Medical Sciences, Tehran, Iran

2. Health Managers Development Institute, Ministry of Health and Medical Education, Tehran, Iran
}

The NMR in Iran has been significantly declined in past decades from 27 deaths in every 1000 live births in 1990 to 10 in 2015 (4). But the decreasing trend slowed down recently (7) and some neighboring and regional countries have surpassed it (4).

To reduce the NMR, the first step is to identify its risk factors (8). Even if we control some of the identified risk factors, fewer newborns will be lost, and fewer parents will experience the grief, sorrow, and mental and social damage of losing a newborn (9).

Numerous studies took place in Iran on risk factors of neonatal mortality, and various factors are reported to be predictive. Yet, working on all risk factors is not easily

$\uparrow$ What is "already known" in this topic:

Reducing neonatal mortality is the key to reduce the overall under-five mortality to achieve the SDG 3.

$\rightarrow$ What this article adds:

This study identified a list of risk factors of neonatal mortality in Iran and divided them into modifiable and identifiable ones. 
possible for the governments. Also relying upon the findings of individual studies may cause problems (10). In addition, the search of the literature did not result in a review of the risk factors of neonatal mortality in Iran or the countries of the region. So in this paper, we tried to systematically review the literature to identify the key risk factors of the neonatal mortality in Iran.

\section{Methods}

Search performed in Persian (the formal language of the country) on national databases and in English on international ones. Databases of SID, Magiran, IranMedex, IranDoc and Google Scholar search engine were searched for Persian publications and Scopus, Science Direct, PubMed, Ovid, EMBASE, ISI web of science and Cochrane for the English ones. The search was done in January 2017 with no time limit. Keywords were "neonate*", "newborn*", "mortality*", "death*", "Iran" and their Persian equivalents. To increase the sensitivity of the search, we did not use "risk factor" in the search strategy. Reference check of the included papers performed by hand search. Google Scholar's citation was used for citation check of the included papers. Retrieved articles pooled in EndNote X7 software and the duplicates identified and removed. An example of search strategy which applied in PubMed is: (((mortality[Title/Abstract]) AND Iran[Title/Abstract] $))$ AND ((newborn[Title/Abstract]) OR neonat*[Title/Abstract]).

Inclusion criteria were studies with a control group, multivariate regression and investigating at least one risk factor for neonatal mortality in Iran. Exclusion criteria were studies limited to a special group of neonates such as newborns having infection or prematurity or low birth weight (LBW), studies with any form of intervention, case reports, studies on perinatal mortality without separating stillbirth and neonatal death, and studien on the causes of death, not the risk factors. Papers with no full text (such as conference abstracts) were excluded because of no possibility of quality assessment and extraction of all intended data.

Data were extracted from the included papers. With the aim of uniform handling of the data, we used an extraction table. The extraction table was piloted for 3 studies and then revised. The revised table included language, year, title, authors, journal name, study design, study time period, study place and population, sampling method, sample size, data collection method, statistical tests used, and the findings.

All included studies were case-control studies, and no cohort study was found. To choose the appropriate tool for quality appraisal, we used the systematic review by Zeng et al. (11). They have recommended "Newcastle-Ottawa Scale" for case-control studies (12). Scores of the quality less than $33 \%$ considered as poor, $33 \%$ to $67 \%$ as moderate, and above $67 \%$ as good quality.

Content analysis method, as a way to analyze text data, was used to analyze the intended data. Risk factors of neonatal mortality divided into two main groups of modifiable and identifiable factors and then to four categories of neonatal factors, maternal and pregnancy factors, factors related to birth and hospital, and the socio-economic factors. The modifiable factors were defined as situations that can be changed either by the parents or the health care providers before and during the pregnancy. The identifiable factors were defined as situations that totally cannot be changed (such as the gender of the baby), cannot be changed in the short term, or are very hard to change.

Neonatal mortality is defined by the World Health Organization (WHO) as the death of newborns that born alive and dead before the day 28 of life (13). In this study, we used the WHO definition.

We tried to do a meta-analysis on odds ratios (ORs) to produce a pooled effect estimate for the identified risk factors and to calculate the population-attributable risk for them. We assessed the heterogeneity of the studies by considering the design and population of the studies and also by the $\mathrm{I}^{2}$ statistics. Some studies had performed conditional logistic regression while others had done it without condition. So there was methodological heterogeneity. Study populations also varied (hospital, rural, all population) and there was clinical heterogeneity (14). So Random Effect model applied for meta-analysis. The $\mathrm{I}^{2}$ statistics showed high heterogeneity among the included studies. But the number of ORs reported for individual risk factors was low and it was impossible to do sensitivity analysis. Thus we put aside the results of the metaanalysis and satisfied with the qualitative review of the evidence.

\section{Results}

A total of 1713 articles were retrieved and finally eight of them were included in the study. Figure 1 shows the diagram of the searching and screening process of the studies. Of the included studies one study had a good and seven studies had moderate quality.

Modifiable factors related to neonatal mortality in Iran are presented in Table 1. As it can be seen, among them gestational age, birth weight, and mother's age had been investigated in more studies. According to Table 1, prematurity, LBW and smoking/addiction had the biggest effect on neonatal mortality in Iran. Mother's body mass

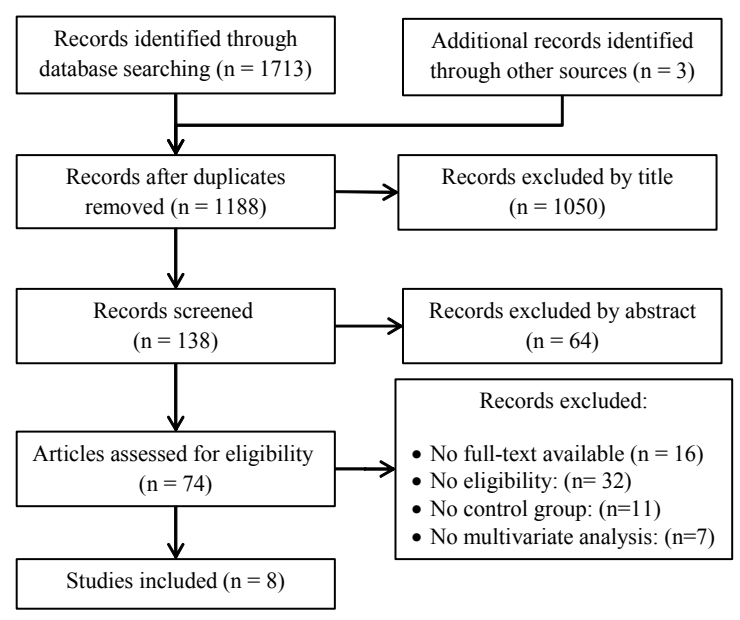

Fig. 1. Search and screening diagram of references for systematic review of risk factors of neonatal mortality in Iran 
Table 1. Modifiable risk factors of neonatal mortality in Iran and their frequency

\begin{tabular}{|c|c|c|c|}
\hline \multirow{2}{*}{ Category } & \multirow{2}{*}{ Risk factor } & \multicolumn{2}{|c|}{ Statistical correlation with neonatal death } \\
\hline & & Yes & No \\
\hline \multirow{2}{*}{ Neonatal risk factors } & Gestational age (prematurity) & $* * * *$ & * \\
\hline & Low birth weight & $* * * * *$ & * \\
\hline \multirow{2}{*}{$\begin{array}{l}\text { Maternal and pregnancy risk } \\
\text { factors }\end{array}$} & Mother's BMI & & * \\
\hline & Birth interval & $* *$ & $* *$ \\
\hline \multirow[t]{4}{*}{ Birth and hospital risk factors } & Cesarean section & * & $* *$ \\
\hline & Vaginal delivery & $* *$ & \\
\hline & Birth attendant & & * \\
\hline & Childbirth in hospital & & $* *$ \\
\hline \multirow[t]{3}{*}{ Socio-economic risk factors } & Smoking and passive smoking & $* *$ & \\
\hline & Addiction of mother & * & \\
\hline & Father's addiction & * & \\
\hline
\end{tabular}

Table 2. Identifiable risk factors of neonatal mortality in Iran and their frequency

\begin{tabular}{|c|c|c|c|}
\hline \multirow[t]{2}{*}{ Category } & \multirow[t]{2}{*}{ Risk factor } & \multicolumn{2}{|c|}{ Statistical correlation with neonatal death } \\
\hline & & Yes & No \\
\hline \multirow[t]{9}{*}{ Neonatal risk factors } & Height & & * \\
\hline & Low Apgar score & * & * \\
\hline & Male gender & * & *** \\
\hline & Blood group & & * \\
\hline & Twin/multiple pregnancy & * & ** \\
\hline & Congenital anomaly & $* * *$ & \\
\hline & Birth asphyxia & $* *$ & * \\
\hline & Hospitalization & & * \\
\hline & Respiratory problems & & * \\
\hline \multirow[t]{15}{*}{ Maternal and pregnancy risk factors } & Mother's height less than $150 \mathrm{~cm}$ & & * \\
\hline & Mother's age less than 20 or more than 35 & * & $* * * *$ \\
\hline & Number of pregnancy/childbirth & $* *$ & $* * * *$ \\
\hline & Premature rupture of membranes & & * \\
\hline & Placenta Previa & & * \\
\hline & History of neonatal death & * & * \\
\hline & History of stillbirth or abortion & & * \\
\hline & History of preterm birth & & * \\
\hline & Polyhydramnios & * & \\
\hline & Oligohydramnios & & * \\
\hline & Placental abruption & * & \\
\hline & High risk pregnancy & $* *$ & \\
\hline & Eclampsia/ pre-eclampsia & & * \\
\hline & No exclusive breastfeeding & * & \\
\hline & Use of corticosteroids during pregnancy & & * \\
\hline Birth and hospital risk factors & Hard delivery & & * \\
\hline \multirow[t]{7}{*}{ Socio-economic risk factors } & Place of living & & * \\
\hline & Employed mother (not housewife) & & * \\
\hline & Father's job & & * \\
\hline & Father's education & & $* * *$ \\
\hline & Number of household members & & * \\
\hline & Mother's education & * & $* *$ \\
\hline & Consanguinity & * & $* * *$ \\
\hline
\end{tabular}

index (BMI), the birth attendant, and childbirth in the hospital found to have no correlation with neonatal mortality in Iran.

Table 2 shows those risk factors of neonatal mortality which are not modifiable but are identifiable. Number of pregnancy/childbirth, male gender, and consanguinity were investigated more than other factors. It seems that congenital anomaly, birth asphyxia, and high-risk pregnancy have bigger effects on neonatal mortality in Iran.

Characteristics of the included studies are presented in Table 3.

\section{Discussion}

This study reviewed the risk factors of neonatal mortality in Iran. The most important risk factors were prematurity, LBW, smoking and addiction of mother, and anomaly. The review identified an expanded list of potential risk factors for neonatal mortality which can be a basis for the future. Future studies on neonatal mortality may consider these factors for data collection and analysis. Yet the findings on most of the risk factors were contradictious. Majority of the identified risk factors were investigated in only one or two studies. On the other hand, considering 
Table 3. Characteristics of the included studies and the investigated risk factors

\begin{tabular}{|c|c|c|c|c|c|c|c|c|}
\hline \multirow[t]{2}{*}{ Author / Year } & \multirow[t]{2}{*}{ Lang. } & \multirow{2}{*}{$\begin{array}{l}\text { Study } \\
\text { Period }\end{array}$} & \multirow{2}{*}{$\begin{array}{l}\text { N. Neona- } \\
\text { tal Death }\end{array}$} & \multirow{2}{*}{$\begin{array}{l}\text { N. Con- } \\
\text { trol } \\
\text { Group }\end{array}$} & \multirow{2}{*}{$\begin{array}{l}\text { Hospital/ } \\
\text { Population- } \\
\text { based }\end{array}$} & \multirow[t]{2}{*}{ Quality $^{\#}$} & \multicolumn{2}{|c|}{ Risk factors' correlation with neonatal mortality ${ }^{\alpha}$} \\
\hline & & & & & & & Yes & No \\
\hline $\begin{array}{l}\text { Sharifzadeh } \\
2003 \text { (15) }\end{array}$ & PR & 2 years & 90 & 180 & Population & $\begin{array}{l}\text { Good } \\
(75 \%)\end{array}$ & $\begin{array}{l}\text { - Smoking } \\
\text { - Opium addiction } \\
\text { - Father's addiction to opium } \\
\text { - Mother's age less than } 20 \text { in the } \\
\text { - first pregnancy } \\
\text { - Prematurity } \\
\text { - Low birth weight } \\
\text { - History of neonatal death } \\
\text { - } \text { No exclusive breast feeding }\end{array}$ & $\begin{array}{l}\text { - Gender } \\
\text { - Father's literacy } \\
\text { - History of abortion/ } \\
\text { stillbirth } \\
\text { - Number of pregnan- } \\
\text { cies } \\
\text { - Birth order } \\
\text { - Mother's age } \\
\text { - Birthplace } \\
\text { - Birth attendant } \\
\text { - Delivery method } \\
\text { - Birth interval } \\
\text { - Mother's education } \\
\text { - Number of household } \\
\text { members }\end{array}$ \\
\hline $\begin{array}{l}\text { Khani } 2007 \\
\text { (16) }\end{array}$ & PR & 3 years & 119 & 381 & Hospital & $\begin{array}{l}\text { Moderate } \\
(62.5 \%)\end{array}$ & $\begin{array}{l}\text { - Gestational age } \\
\text { - Birth weight } \\
\text { - Mother's education } \\
\text { - Polyhydramnios } \\
\text { - Vaginal delivery } \\
\text { - Congenital anomaly }\end{array}$ & $\begin{array}{l}\text { - Number of deliveries } \\
\text { - Mother's job } \\
\text { - Father's job } \\
\text { - Father's education } \\
\text { - Multiple pregnancies } \\
\text { - Oligohydramnios } \\
\text { - Using corticosteroids } \\
\text { during pregnancy }\end{array}$ \\
\hline $\begin{array}{l}\text { Chaman } 2008 \\
*(17)\end{array}$ & PR & 1 year & 97 & 97 & Population & $\begin{array}{c}\text { Moderate } \\
(62.5 \%)\end{array}$ & $\begin{array}{l}\text { - High-risk pregnancy } \\
\text { - Cesarean section } \\
\text { - Low birth weight }\end{array}$ & $\begin{array}{l}\text { - Mother's illiteracy } \\
\text { - Father's illiteracy } \\
\text { - Gestational age }\end{array}$ \\
\hline $\begin{array}{l}\text { Chaman } 2009 \\
\text { * (18) }\end{array}$ & EN & 1 year & 97 & 97 & Population & $\begin{array}{l}\text { Moderate } \\
(62.5 \%)\end{array}$ & $\begin{array}{l}\text { - Low birth weight } \\
\text { - Prematurity } \\
\text { - Cesarean section } \\
\text { - Child } 4 \text { or more } \\
\text { - A birth interval less than } 24 \\
\text { months }\end{array}$ & $\begin{array}{l}\text { - Gender } \\
\text { - Mother's age }\end{array}$ \\
\hline $\begin{array}{l}\text { Mohaddesi } \\
2013(19)\end{array}$ & EN & 3 years & 250 & 250 & Hospital & $\begin{array}{l}\text { Moderate } \\
(50 \%)\end{array}$ & $\begin{array}{l}\text { - Apgar score below } 6 \text { in the first } \\
\text { minute } \\
\text { - Birth asphyxia } \\
\text { - Vaginal delivery } \\
\text { - Congenital anomaly } \\
\text { - Number of deliveries (respec- } \\
\text { tively: first, six and more, four } \\
\text { and five, two and three) }\end{array}$ & $\begin{array}{l}\text { - Low birth weight } \\
\text { - Gender } \\
\text { - Blood group of new- } \\
\text { born } \\
\text { - History of preterm } \\
\text { birth } \\
\text { - Consanguinity }\end{array}$ \\
\hline
\end{tabular}

the reported ORs on these factors, it can be said that the evidence on risk factors of neonatal mortality in Iran is insufficient. Thus we recommend more studies in this regard.

The maternal and pregnancy risk factors and the socioeconomic ones were investigated less than other factors, probably due to the retrospective nature of the studies and chart review method of data collection. Some socioeconomic factors such as ethnicity, income level, and social class also were not examined in the reviewed papers while they are reported to have an effect (23-25).

Gestational age identified as a risk factor of neonatal mortality in Iran. WHO had introduced preterm birth as one of the most important risk factors of the neonatal mortality (26). A study on preterm neonates in Iran found that higher gestational age was correlated with lower neonatal death (27). Preterm birth is reported to be correlated with unwanted pregnancy, not receiving pregnancy care, not attending educational courses during pregnancy, mother's age, obesity, underweight, preeclampsia, premature rupture of membranes, cesarean section, history of preterm baby, low socioeconomic status, and living in rural area $(24,27-32)$. Thus it is, at least to some extent, modifiable. Furthermore increasing the quality of care before, within and between pregnancies may reduce the prevalence of preterm birth (26) and special care of such newborns may reduce their mortality (33). Vakilian et al. in a systematic review and meta-analysis reported the prevalence of preterm birth (before 37 weeks) in Iran to be 9.2\% (34).

This review found the LBW as one of the main risk factors of the neonatal mortality in Iran. It is reported to be a risk factor in other countries too (35). LBW is also a risk factor for infant mortality (36). It is associated with preterm birth, mother's weight less than $50 \mathrm{Kg}$, BMI less 
A. Daemi, et al.

Table 3. Ctd

\begin{tabular}{|c|c|c|c|c|c|c|c|c|}
\hline \multirow[t]{2}{*}{ Author / Year } & \multirow[t]{2}{*}{ Lang. } & \multirow{2}{*}{$\begin{array}{l}\text { Study } \\
\text { Period }\end{array}$} & \multirow{2}{*}{$\begin{array}{l}\text { N. Neonatal } \\
\text { Death }\end{array}$} & \multirow{2}{*}{$\begin{array}{l}\text { N. Control } \\
\text { Group }\end{array}$} & \multirow{2}{*}{$\begin{array}{c}\text { Hospital / } \\
\text { Population-based }\end{array}$} & \multirow[t]{2}{*}{ Quality $^{\#}$} & \multicolumn{2}{|c|}{ Risk factors' correlation with neonatal mortality ${ }^{\alpha}$} \\
\hline & & & & & & & Yes & No \\
\hline $\begin{array}{l}\text { Chaman } 2014 \\
*(20)\end{array}$ & $\mathrm{EN}$ & 1 year & 97 & 97 & Population & $\begin{array}{c}\text { Moderate } \\
(62.5 \%)\end{array}$ & $\begin{array}{l}\text { - Low birth weight } \\
\text { - Prematurity } \\
\text { - Close consanguinity } \\
\text { (first cousin) } \\
\text { - Birth order } 4 \text { and } \\
\text { more } \\
\text { - Cesarean section } \\
\text { - A birth interval less } \\
\text { than } 24 \text { months }\end{array}$ & - Second cousin \\
\hline $\begin{array}{l}\text { Kose Gharavi } \\
2016(21)\end{array}$ & PR & 3 years & 52 & 201 & Population & $\begin{array}{l}\text { Moderate } \\
(62.5 \%)\end{array}$ & $\begin{array}{l}\text { - Low birth weight } \\
\text { - Male gender }\end{array}$ & $\begin{array}{l}\text { - Birth in hospital } \\
\text { - Birth order } \\
\text { - Delivery method } \\
\text { - Mother's age } \\
\text { - Place of residence } \\
\text { - Consanguinity } \\
\text { - Number of deliveries } \\
\text { - Birth interval } \\
\text { - Mother's BMI } \\
\text { - History of child death }\end{array}$ \\
\hline $\begin{array}{l}\text { Ghotbi } 2017 \\
(22)\end{array}$ & $\mathrm{EN}$ & 1 year & 181 & 362 & Population & $\begin{array}{l}\text { Moderate } \\
(62.5 \%)\end{array}$ & $\begin{array}{l}\text { - Gestational age } \\
\text { - Birth weight } \\
\text { - Anomaly } \\
\text { - Asphyxia } \\
\text { - Passive smoking } \\
\text { - Birth interval less } \\
\text { than } 3 \text { years } \\
\text { - Multiple pregnancies } \\
\text { - Placental abruption }\end{array}$ & $\begin{array}{l}\text { - Newborn's height } \\
\text { - Need to resuscitation } \\
\text { - Respiratory problems } \\
\text { - Apgar score } \\
\text { - Hospitalization } \\
\text { - Hard labor } \\
\text { - Multiple childbirth } \\
\text { - Mother's age less than } \\
\text { - Mother's age more } \\
\text { - } 18 \\
\text { - Gravidity } 5 \text { or more } \\
\text { - First gravidity } \\
\text { - Mother's height less } \\
\text { - } \text { than } 150 \\
\text { - Elacenta previa } \\
\text { - Preeclampsia/ } \\
\text { Premature rupture of } \\
\text { membranes }\end{array}$ \\
\hline
\end{tabular}

EN: English; PR: Persian; *: publications with the same dataset; \#: quality scores provided based on Newcastle-Ottawa Scale; $\alpha$ : based on multivariate regression

than 19.8, underweight, multiple pregnancies, birth spacing less than two years, history of LBW, high blood pressure in pregnancy, premature rupture of membranes, low weight gain in pregnancy, and nutrition in the third trimester of the pregnancy $(10,28,37-40)$. So it can be reduced by proper interventions. A study in Taiwan showed that economic growth leads to lower rates of LBW. The study also found that the social class is effective in the rate of LBW (41). Prevalence of the LBW in different cities of Iran has been reported to be $8.7 \%$ in Ahwaz, $7.7 \%$ in Babol, $8.5 \%$ in Shahrekord, and 7.9\% in Birjand $(37,42-44)$.

The findings were contradictious about the delivery method. Some studies reported the cesarean section and others reported vaginal delivery as the risk factor of neonatal mortality (Table 1). To assure the safety of newborns and mothers, the WHO recommends a rate of 5 to 15 percent of births to be cesarean (45). But the rate was $48 \%$ in Iran during the years 2000 and 2012 as a systematic review and meta-analysis showed (46). This high rate of cesarean indicates that a considerable proportion of them are elective and have no medical indication. A study in Nigeria also found an association between cesarean and neonatal mortality (47). Despite the low-income countries, middle-and-high income countries have higher rates of cesarean, and in this situation, no correlation is observed between the cesarean rate and the NMR (48).

Smoking, passive smoking, and opium addiction by the pregnant mothers had direct correlations with neonatal mortality. Previous studies also had reported some other consequences for smoking during pregnancy; such as stillbirth, preterm birth, and $\operatorname{LBW}(10,49,50)$. Thus it is necessary to increase the awareness of the mothers through education and consultation and also to provide support for quitting smoking before the pregnancy (10, 51). Moreover, in some areas of the country due to traditional beliefs, families give opium to the newborn with therapeutic purposes. This leads, in some cases, to death of the newborn $(15,21)$. It is needed to raise awareness in this regard too (21).

In this review, the retrieved risk factors categorized into modifiable and identifiable ones. Yet some of the identifiable factors might be modifiable on the long term. Appropriate interventions are needed for modifiable factors. On the identifiable factors, efforts must concentrate on early 
detection during pregnancy and on birth and then special attention and care. A good and practical example in this regard is the Apgar score. Since the Apgar score is, as a routine, calculated for all Iranian newborns in the hospitals and delivery facilities, newborns with low Apgar score can be easily identified. A study in Brazil also found Apgar score a predictor of neonatal mortality (52). Other studies in Iran reported the scores of SNAP-PE II tool as a predictor of neonatal mortality $(53,54)$. Heidarzadeh et al. designed and implemented a system for identification and follow up of the high-risk infants in Tabriz, Iran which was successful in identifying the cases and reducing the consequences $(55,56)$. Other studies have emphasized early detection of high-risk pregnancies, giving more attention to them and providing educational programs (10, 57).

Since $44 \%$ of the total neonatal deaths occur in the first day of birth, $62 \%$ in first three days, and $77 \%$ in the first week (58), it is suggested that special attention to be devoted to the newborns in these early days of life to save them. As it is stated in the above paragraph, proper care of the high-risk newborns can lead to reduced number of neonatal deaths. Yet, a study by Batieha et al. in 18 hospitals in Jordan showed that only $37 \%$ of the newborns received optimum care during the pregnancy and after birth (6). Another study in Colombia found a correlation between having health insurance and the lower rate of neonatal death (59) which is probably related to financial access to prenatal and post-natal care.

\section{Limitations}

This review had some limitations. Sample size of most of the included studies was small. Majority of the studies were hospital-based. Moreover, the number of reported ORs for each risk factor was low. So we recommend conducting large population-based studies with multivariate regression and reporting OR.

\section{Conclusion}

Preterm birth, LBW, smoking and addiction of mother, and anomaly were the important risk factors of neonatal mortality in Iran. Some other factors also were identified as potential risk factors. Yet, in general, the evidence was not strong and sufficient on the effect size of them, and there is a need for more population-based studies. On the modifiable risk factors, proper interventions and on the identifiable ones, early detection, and special care might prevent the newborns from death and thus help to lower the NMR.

\section{Acknowledgments}

The authors would like to thank Dr. Mohammad AsghariJafarabadi, Dr. Masoud Salehi, and Mr. Masoud Behzadifar for their help in preparing the manuscript draft. This study is part of a Ph.D. thesis in Health Policy in Iran University of Medical Sciences (IUMS). The project is supported by the IUMS by the contract number IUMS/SHMIS_1395/9221557210. The sponsor of the study had no role in the design of the study, data collection, analysis, interpretation, and the final report.
Conflict of Interests

The authors declare that they have no competing interests.

\section{References}

1. Lozano R, Wang H, Foreman KJ, Rajaratnam JK, Naghavi M, Marcus $\mathrm{JR}$, et al. Progress towards Millennium Development Goals 4 and 5 on maternal and child mortality: an updated systematic analysis. The Lancet. 2011;378(9797):1139-65.

2. Sustainable development goals. United Nations; [cited 2016 31/10/2016]; Available from: http://www.un.org/sustainabledevelop ment/

3. Jafari F, Eftekhar H, Pourreza A, Mousavi J. Socio-economic and medical determinants of low birth weight in Iran: 20 years after establishment of a primary healthcare network. Public Health. 2010;124(3):153-8.

4. You D, Hug L, Ejdemyr S, Beise J, Idele P. Levels and trends in child mortality. Report 2015. Estimates developed by the UN Inter-agency Group for Child Mortality Estimation: United Nations Children's Fund; 2015.

5. Lawn JE, Kerber K, Enweronu-Laryea C, Cousens S. 3.6 million neonatal deaths - what is progressing and what is not? Semin Perinatol. 2010;34(6):371-86.

6. Batieha AM, Khader YS, Berdzuli N, Chua-Oon C, Badran EF, Alsheyab NA, et al. Level, causes and risk factors of neonatal mortality, in Jordan: results of a national prospective study. Matern Child Health J. 2016;20(5):1061-71

7. Neonatal mortality indicators in Iran and its distribution within country (2013-2015). Tehran, Iran: Office for Neonatal Health, Office for Family and Population Health, Deputy of Health, Ministry of Health and Medical Education; 2016.

8. Moura PMSS, Maestá I, Rugolo LMSS, Angulski LFRB, Caldeira AP, Peraçoli JC, et al. Risk factors for perinatal death in two different levels of care: a case-control study. Reprod Health. 2014;11(1):11.

9. Hawthorne DM, Youngblut JM, Brooten D. Parent Spirituality, Grief, and Mental Health at 1 and 3Months After Their Infant's/Child's Death in an Intensive Care Unit. J Pediatr Nurs. 2016;31(1):73-80.

10. Flenady V, Koopmans L, Middleton P, Frøen JF, Smith GC, Gibbons K, et al. Major risk factors for stillbirth in high-income countries: a systematic review and meta-analysis. Lancet. 2011;377(9774):1331-40.

11. Zeng X, Zhang Y, Kwong JS, Zhang C, Li S, Sun F, et al. The methodological quality assessment tools for preclinical and clinical studies, systematic review and meta-analysis, and clinical practice guideline: a systematic review. J Evid Based Med. 2015;8(1):2-10.

12. Wells G, Shea B, O'connell D, Peterson J, Welch V, Losos M, et al. The Newcastle-Ottawa Scale (NOS) for assessing the quality of nonrandomised studies in meta-analyses. Ottawa: Ottawa Hospital Research Institute. 2011 [April 2017]; Available from: http://www.ohri.ca/programs/clinical_epidemiology/oxford.asp.

13. Global reference list of 100 core health indicators. World Health Organization. 2015:28.

14. Higgins JP, Green S. Cochrane handbook for systematic reviews of interventions: John Wiley \& Sons; 2011.

15. Sharifzadeh G, Ayatollahi A, RajayiFard A, Namakin K. Epidemiologic study of neonatal mortality and its related factors in rural areas affiliated to health houses of Birjand. J Birjand Univ Med Sci. 2003;10(3):9-15. [in Persian].

16. Khani S, Mohamadpour RA, Ghaffari Saravi V, Abdollahi F, sabaghi R, bavand M. Neonatal survival rate and its related factors in the NICU of public and private hospitals in Sari by survival analysis technique during 2005-2007. J Mazandaran Univ Med Sci. 2008;17(62):54-62. [in Persian].

17. Chaman R, Yunesian M, Golestan B, Holakouie Naieni K. Evaluation of the effects of high-risk pregnancy on neonatal mortality in a rural area of Iran: a nested case-control study. Iran J Epid. 2008;3(3):1-6. [in Persian].

18. Chaman R, Naieni KH, Golestan B, Nabavizadeh H, Yunesian M. Neonatal mortality risk factors in a rural part of Iran: a nested casecontrol study. Iran J Public Health. 2009;38(1):48-52.

19. Mohaddesi H, Khalkhali H, Fakor Z, Azadi J. Investigating the effects of the neonatal factors and therapeutic modalities on neonatal mortality in neonatal intensive care unit of Shahid Motahhari haspital, Urmia. Iran J Nurs Midwifery Res. 2013;19(5):485-90. 
20. Chaman R, Taramsari MG, Khosravi A, Amiri M, Naieni KH, Yunesian M. Consanguinity and neonatal death: a nested case-control study. J Fam Rep Health. 2014;8(4):189-93.

21. Kose Gharavi AG, Shoraka HR, Sofizadeh A, Eimani Katuli H. Neonatal mortality risk factors in Maraveh Tapeh County in Golestan province, north of Iran (2011-13). J Gorgan Univ Med Sci. 2016;18(1):86-93. [in Persian].

22. Ghotbi N, Zokai M, Rahmani K, Vakili FZ, Zandi S, Asadi N, et al. Risk factors related to the neonatal mortality in Kurdistan Province, Iran: A population-based case-control study. Shiraz E-Med J. 2017;18(3).

23. Loggins S, Andrade FCD. Despite an overall decline in US infant mortality rates, the black/white disparity persists: recent trends and future projections. J Community health. 2014;39(1):118-23

24. Eshghizadeh M, Moshki M, Majeedi Z, Abdollahi M. Modifiable risk factors on preterm birth: A case-control study. Horiz Med Sci. 2015;21(2):141-6.

25. Gizaw M, Molla M, Mekonnen W. Trends and risk factors for neonatal mortality in Butajira District, South Central Ethiopia,(19872008): a prospective cohort study. BMC pregnancy childbirth. 2014;14(1):64.

26. Born too soon: the global action report on preterm birth: World Health Organization2012. Report No.: 9244503433.

27. Pourarian S, Vafafar A, Zareh Z. The incidence of prematurity in the hospital of Shiraz University of Medical Sciences and health services, 1999. Razi J Med Sci. 2002;9(28):19-25.

28. Han Z, Mulla S, Beyene J, Liao G, McDonald SD. Maternal underweight and the risk of preterm birth and low birth weight: a systematic review and meta-analyses. Int J Epidemiol. 2010;40(1):65101.

29. McDonald SD, Han Z, Mulla S, Beyene J. Overweight and obesity in mothers and risk of preterm birth and low birth weight infants: systematic review and meta-analyses. BMJ. 2010;341:c3428.

30. Guimarães EAdA, Vieira CS, Nunes FDD, Januário GdC, Oliveira VCd, Tibúrcio JD. Prematurity and associated factors in Divinópolis, Minas Gerais state, Brazil, 2008-2011: analysis of the Information System on Live Births. Epidemiologia e Serviços de Saúde. 2017;26(1):91-8.

31. do Carmo Leal M, Esteves-Pereira AP, Nakamura-Pereira M, Torres JA, Theme-Filha M, Domingues RMSM, et al. Prevalence and risk factors related to preterm birth in Brazil. Rep Health. 2016;13(3):127.

32. Namakin K, Sharifzadeh G, Malekizadeh A. To Identify the risk factors in prematurity birth in Birjand, Iran: A case - control study. Iran J Epidemiol. 2011;7(3):1-5

33. Boskabadi H, Parvini Z, Barati T, Moudi A. Study of the causes and predisposing factors in neonatal mortality in Ghaem Hospital (March 2009 to May 2010). Iran J Obstet Gynecol Infertil. 2012;14(7):6-14. [in Persian].

34. Vakilian K, Ranjbaran M, Khorsandi M, Sharafkhani N, Khodadost M. Prevalence of preterm labor in Iran: A systematic review and meta-analysis. Int J Rep BioMed. 2015;13(12):743.

35. Wardlaw TM .Low birthweight: country, regional and global estimates: UNICEF; 2004.

36. Ansari-Moghaddam A, Sadeghi-Bojd S, Imani M, Movahedinia S, Pourrashidi A, Mohammadi M. A multivariate analysis of factors associated with infant mortality in South-East of Iran .J Pak Med Assoc. 2014;64(10):1123-6.

37. Faghih S, Hejazi E. Assessment of birth weight and its related factors among infants born in the hospitals of Ahwaz Jondishapour University. J Health Sci Surveill Syst. 2014;2(1):26-9.

38. Mirzarahimi M, Saadati H, Barak M, Abbasgholizadeh N, Azami A, Enteshari A. Incidence and risk factors of low-birth-weight infants. J Ardabil Univ Med Sci. 2009;9(1):69-79.

39. Delvarian-zadeh $M$, Bolbol Haghighi N, Ebrahimi $H$. The relationship between nutritional status of mothers in their third trimester and delivery of low birth weight infants. Arak Med Univ J. 2007;10(1):54-63.

40. Madadzadeh M, Feizi Z, Hajikazemi E, Haghani H. Mothers' hypertension and neonatal birth weight. Iran J Nurs. 2005;18(41):1725.

41. Li C, Sung F. Socio-economic inequalities in low-birth weight, fullterm babies from singleton pregnancies in Taiwan. Public Health. 2008;122(3):243-50.

42. Delaram M. The incidence and related factors of low birth weight Iran J Nurs. 2010;23(64):29-36.
43. Taheri F, Kazemi T. Risk factors for low birth weight in Birjand, Iran (a case-control study). J Birjand Univ Med Sci. 2007;14(3):9-15. 44. Zahed Pasha Y, Esmaeili Dooki M, Haji Ahmadi M, Asgardon G, Ghadimi R, Baleghi M, et al. Effect of risk factors on low birth weight neonates. J Babol Univ Med Sci. 2004;6(2):18-24

45. Gibbons L, Belizán JM, Lauer JA, Betrán AP, Merialdi M, Althabe F. The global numbers and costs of additionally needed and unnecessary caesarean sections performed per year: overuse as a barrier to universal coverage. World Health Report. 2010;30:1-31.

46. Azami-Aghdash S, Ghojazadeh M, Dehdilani N, Mohammadi M. Prevalence and causes of cesarean section in Iran: systematic review and meta-analysis. Iran J Public Health. 2014;43(5):545.

47. Ezeh OK, Agho KE, Dibley MJ, Hall J, Page AN. Determinants of neonatal mortality in Nigeria: evidence from the 2008 demographic and health survey. BMC Public Health. 2014;14(1):521.

48. Althabe F, Sosa C, Belizán JM, Gibbons L, Jacquerioz F, Bergel E. Cesarean section rates and maternal and neonatal mortality in low-, medium-, and high-income countries: an ecological study. Birth. 2006;33(4):270-7.

49. Akl EA, Gaddam S, Gunukula SK, Honeine R, Jaoude PA, Irani J. The effects of waterpipe tobacco smoking on health outcomes: a systematic review. Int J Epidemiol. 2010;39(3):834-57.

50. Sadat Z, Bazarganipour F, Sehhat Z, Barati M. The relationship between maternal environmental tobacco smoke exposure during pregnancy with anthropometric parameters of the newborn. Qom Univ Med Sci J. 2008;2(4):35-42.

51. Esmaili H, Shah Farhat A, Mirzai Najmabadi K, Dadgar S, Karimi A, Khojasteh Gelayami M. The relationship between maternal body mass index at the beginning of pregnancy and Infants' birth weight and pregnancy outcomes. Iran $\mathrm{J}$ Obstet Gynecol Infertil. 2014;16(85):1-10

52. Oliveira TGd, Freire PV, Moreira FT, Moraes JdSBd, Arrelaro RC, Rossi S, et al. Apgar score and neonatal mortality in a hospital located in the southern area of São Paulo City, Brazil. Einstein (São Paulo). 2012;10(1):22-8.

53. Babaei H, Alipour A, Moradifaradinbeh L, Rezaei M. Assessment of the SNAP-II score and other factors for predicting the fate of admitted neonates to the neonatal intensive care unit (NICU) of Imam Reza Hospital in Kermanshah. ZUMS Journal. 2012;20(83):78-89. [in Persian].

54. Kadivar M, Sagheb S, Bavafa F, Moghadam L, Eshrati B. Neonatal mortality risk assessment in a neonatal intensive care unit (NICU). Iran J Pediatr. 2007;17(4):325-32.

55. Heidarzadeh M, Jodeiry B, Hosseini MB, Mirnia K, Akrami F, Habbibollahi A, et al. High risk infants follow-up: a case study in Iran. Int J Pediatr. 2015;2015.

56. Jodeiry B, Heidarzadeh M, Mirnia K, Akrami F, Heidarabadi S, Ebadi A. Innovation of high?risk infants follow? up surveillance system in Iran. Int J Prev Med. 2015;6(35).

57. Mirzarahimi M, Abedi A, Shahnazi F, Saadati H, Enteshari A. Causes and rate of mortality among the newborns in NICU and newborns unit at Imam Khomeini and Alavi Hospitals in Ardabil from september 2006 to september 2007. J Ardabil Univ Med Sci 2008;8(4):424-30

58. Sankar M, Natarajan C, Das R, Agarwal R, Chandrasekaran A, Paul $\mathrm{V}$. When do newborns die? A systematic review of timing of overall and cause-specific neonatal deaths in developing countries. J Perinatol. 2016;36(S1):S1

59. Houweling TA, Arroyave I, Burdorf A, Avendano M. Health insurance coverage, neonatal mortality and caesarean section deliveries: an analysis of vital registration data in Colombia. J Epidemiol Community Health. 2017;71(5):505-12. 